\title{
Bilateral Choroidal Metastases from Lung Adenocarcinoma: A Case Report
}

\author{
Hasan Ergenc $^{a} \quad$ Attila Onmez ${ }^{b}$ Ezgi Oymak ${ }^{c}$ Ramiser Tanriseven ${ }^{c}$ \\ Erkan Celik $^{d} \quad$ Funda Ebru Onmez $^{d} \quad$ Ali Tamer $^{a}$ Meltem Baykara $^{\mathrm{e}}$ \\ ${ }^{a}$ Sakarya University Training and Research Hospital, Department of Internal Medicine, \\ Sakarya, Turkey; ${ }^{b}$ Turkey Republic Ministry of Health Kocaali State Hospital, Department \\ of Internal Medicine, Sakarya, Turkey; 'Sakarya University Training and Research Hospital, \\ Department of Radiation Oncology, Sakarya, Turkey; ${ }^{\text {d} S a k a r y a ~ U n i v e r s i t y ~ T r a i n i n g ~ a n d ~}$

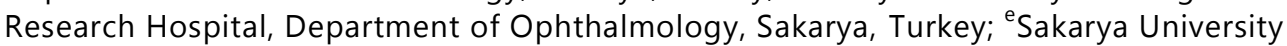 \\ Training and Research Hospital, Department of Medical Oncology, Sakarya, Turkey
}

\section{Keywords}

Choroidal metastasis · Lung cancer · Radiotherapy

\begin{abstract}
The most common malignancy of the eye is metastatic tumors, with choroidal metastases being the majority of them. In women, breast cancer is the most common cause of orbital metastases, and in men, it is lung cancer. Despite the fact that there are efficient treatment options for orbital metastases, the benefit of procedures to detect choroidal metastases is debatable due to the quick progression and poor prognosis of lung cancer. In choroidal metastases resulting from lung cancer, patients are usually presented with decreased sight. Defects in the field of vision, flashes of light and floating bodies generally follow. Treatment options of choroidal metastases include many methods including laser photocoagulation, cryotherapy, chemotherapy, radiotherapy, surgical resection, enucleation and photodynamic therapy. There are reports emphasizing radiotherapy as the most efficient treatment option. In this case report, we sum up the case of a male patient presenting with blurry vision in both eyes, who was subsequently detected to have bilateral choroidal metastatic tumor and was diagnosed with primary lung adenocarcinoma.




\section{Introduction}

The most common form of intraocular malignancies is choroidal metastases [1]. Eightyeight percent of the metastatic foci are detected in the choroid, $9 \%$ in the iris and $2 \%$ in the ciliary body [2]. Typical choroidal metastases are plateau-shaped, cream-colored and occur with subretinal fluid and retinal detachment. Metastatic choroidal lesions are mostly seen in the posterior pole where blood flow is the highest. Sixty-six percent of the patients have a previous systemic cancer history. The most common cause of orbital metastases in women is breast cancer, and in men, it is lung cancer. Treatment of these tumors, which may cause a drastic decrease in sharpness of sight, consists of laser photocoagulation, cryotherapy, chemotherapy, radiotherapy (RT), surgical resection and photodynamic therapy [3]. In small tumors not hindering the sight, treatment response can be achieved with systemic therapy. In symptomatic large lesions, external RT is necessary [4]. We report a case of lung cancer presenting first with symptoms caused by orbital metastases.

\section{Case Report}

In the orbital examination, a 67-year-old male patient coming to the ophthalmologist with complaints of blurry vision showed subretinal fluid and choroidal folding, and these findings were considered as metastatic lesions. The chest X-ray ordered due to the patient's complaints of persistent cough for a couple of months showed a right hilar mass. On thorax computed tomography (CT), multiple nodular lesions in bilateral lungs and left pleural effusion was detected (fig. 1), and a transbronchial bronchoscopic biopsy of the lower posterior lobe of the left lung was determined as primary lung adenocarcinoma. Positron emission tomography (PET)-CT showed a primary involvement in the medial segment of the left lung and widespread hypermetabolic nodules in bilateral lungs, metastatic mediastinal lymphadenopathies and widespread skeletal metastases, the majority in the vertebral column, pelvic bones and in the proximal part of the bilateral femurs. No mass lesions were seen in brain magnetic resonance imaging (MRI). On repeat fundus examination, yellow-white choroidal swelling with irregular borders in the right eye (fig. 2), yellow choroidal lesions and serous retinal detachment in left eye (fig. 3) was observed. In optical coherence tomography (OCT) images, retinal swelling and choroidal irregularities were noticed (fig. 4). Orbital MRI showed plaques of a maximum thickness of $2 \mathrm{~mm}$ with pathologic contrast enhancement in posterolateral regions of the bilateral globes. No pathologic findings were seen in bilateral optic nerve tracts and neural parenchyma. Laser ablation was administered to large lesions. Due to widespread bone pain, palliative RT was given before systemic therapy and zoledronic acid treatment was started. A first palliation of 30 Gy was given to lumbar 4 vertebrae, pelvic bones and the proximal half of the right femur in 12 fractions. The second palliation site was thoracic 5-12th vertebrae treated with $30 \mathrm{~Gy}$ in 10 fractions. External RT to orbitae was started next, with the radiation field excluding the neural parenchyma (fig. 5). After the third fraction of orbital RT, the patient demonstrated involuntary muscle movements, nonsensical speech and impaired balance. Even though not proven radiologically, these findings were evaluated as likely cranial metastases clinically, and the RT plan was revised to cover the cranium and bilateral orbitae to the palliative dose of 30 Gy with 3D conformal RT. During the follow-up period, the performance status of the patient advanced to ECOG performance status 3 , and approximately 4 months after the diagnosis, the patient died because of disease progression. 


\section{Case Reports in Oncology}

\section{Results}

Presentation with blurry vision due to choroidal metastases as initial finding in lung cancer is highly uncommon. Upon detection of choroidal lesions in the fundoscopic examination, the primary tumor must be investigated. In the literature, isolated orbital metastases and treatment of these cases with laser ablation and RT have been reported. In widespread choroidal metastases where laser ablation is inadequate, RT to the orbitae is a treatment option. With 3D conformal RT or intensity-modulated RT, bilateral sparing of lenses is possible while the posterior globe is irradiated sufficiently within normal tissue tolerances. In this case, even though radiologically isolated bilateral orbital metastases were found, rapidly declining performance and development of neurological symptoms of the patient pointed to microscopic cranial metastasis, and palliative RT to bilateral orbitae and to the cranium was given. Systemic chemotherapy could not be started because of declining performance and the patient died due to disease progression. Treatment response of orbital metastases to RT could not be evaluated.

\section{Discussion}

Of the patients presenting with a decrease in sight and detected to have choroidal metastases, $47 \%$ are reported to have breast cancer and $21 \%$ lung cancer [2]. There are very few studies evaluating the incidence of choroidal metastases in lung cancer. This incidence was reported as $7.1 \%$ in a series of 87 lung cancer cases by Kreusel et al. [5]. Despite the fact that there are efficient treatment options for orbital metastases, the benefit of procedures to detect choroidal metastases is debatable due to the quick progression and poor prognosis of lung cancer. In concordance, mediastinal lymphadenopathies and widespread bone metastases were found in our case at diagnosis. Orbital metastases can be an initial finding or detected after the diagnosis of lung cancer [6].

In case of choroidal metastases resulting from lung cancer, patients usually present with decreased sight. Defects in the field of vision, flashes of light and floating bodies generally follow. These secondary symptoms are the result of retinal detachment occurring on or around the lesion. The most common pathology with choroidal metastases is retinal detachment [2]. Metastases arising from lung cancer mostly develop as unilateral and unifocal [7]. Lesions are usually yellow-cream-colored [4, 7]. To determine the nature and spread of the lesions, various methods including fundus fluorescein angiography, ultrasonography, OCT, CT, MRI or fine-needle aspiration biopsy are employed.

Similarly, subretinal fluid and choroidal folding was found in our case. On repeat fundoscopic examination, yellow-white choroidal swelling with irregular borders in the right eye and yellow choroidal lesions and serous retinal detachment in the left eye was observed, and the nature and spread of these lesions were assessed with OCT.

Treatment options of choroidal metastases include many methods including laser photocoagulation, cryotherapy, chemotherapy, RT, surgical resection, enucleation and photodynamic therapy [8]. There are reports emphasizing RT as the most efficient treatment option [9]. In a series of 233 orbital metastases by Rudoler et al. [10], 57\% treated with RT have gained an increase in vision, while $93 \%$ of the patients achieved significant regression of the tumor size or no progression at all. There are also studies reporting chemotherapy as one of the treatment options [11]. 
In solitary and small lesions, or in lesions not responding to RT or chemotherapy, laser photocoagulation or photodynamic therapy should be considered [12]. In our case, large lesions were managed with laser ablation. Due to widespread bone pain, palliative RT was given before systemic therapy and zoledronic acid treatment was administered. Afterwards, palliative RT to bilateral orbitae was started.

In conclusion, while choroidal metastases are a sign of poor prognosis, treatment options should be revised to achieve improvement in visual functions and quality of life. Each patient should be assessed according to his/her respective performance status, stage of the disease, state of present metastatic lesions, tumor type and size in order to choose the appropriate treatment option.

\section{Statement of Ethics}

Informed consent was obtained from the patient.

\section{Disclosure Statement}

There is no conflict of interest.

\section{References}

1 Green WR: Pathology of metastatic tumours to the eye; in Spencer WH (ed): Ophthalmic Pathology. An Atlas and Textbook, ed 4. Philadelphia, WB Saunders, 1996, p 1722.

-2 Shields CL, Shields JA, Gross NE, Schwartz GP, Lally SE: Survey of 520 eyes with uveal metastases. Ophthalmology 1997;104:1265-1276.

3 Augsburger JJ, Guthoff R: Metastatic cancer to the eye; in Yanoff M, Duker JS (eds): Ophthalmology, ed 2. St Louis, Mosby, 2003, pp 1064-1069.

4 Mauget-Faÿsse M, Gambrelle J, Quaranta-El Maftouhi M, Moullet I: Photodynamic therapy for choroidal metastasis from lung adenocarcinoma. Acta Ophthalmol Scand 2006;84:552-554.

-5 Kreusel KM, Wiegel T, Stange M, Bornfeld N, Hinkelbein W, Foerster MH: Choroidal metastasis in disseminated lung cancer: frequency and risk factors. Am J Ophthalmol 2002;134:445-447.

-6 Kocak Z, Tabakoglu E, Benian O, Bayir G, Unlu E, Uzal C: Bilateral choroidal metastases as an initial manifestation of small-cell carcinoma of the lung. Tuberk Toraks 2006;54:61-64.

7 Goldberg RA, Rootman J, Cline RA: Tumors metastatic to the orbit: a changing picture. Surv Ophthalmol 1990;35:1-24.

8 Harbour JW: Photodinamic therapy for choroidal metastasis from carcinoid tumour. Am J Ophthalmol 2004;137:1143-1145.

-9 Demirci H, Shields CL, Chao AN, Shields JE: Uveal metastasis from breast cancer in 264 patients. Am J Ophthalmol 2003;136:264-271.

10 Rudoler SB, Shields CL, Corn BW, De Potter P, Hyslop T, Curran WJ Jr, Shields JA: Functional vision is improved in the majority of patients treated with external beam radiation for choroidal metastases: a multivariate analysis of 188 patients. J Clin Oncol 1997;15:1244-1251.

11 Maturu VN, Singh N, Bansal P, Rai Mittal B, Gupta N, Behera D, Gupta A: Combination of intravitreal bevacizumab and systemic therapy for choroidal metastases from lung cancer: report of two cases and a systematic review of literature. Med Oncol 2014;31:901.

12 Amer R, Pe'er J, Chowers I, Anteby I: Treatment options in the management of choroidal metastases. Ophthalmologica 2004;218:372-777. 


\section{Case Reports in Oncology}

\begin{tabular}{l|l}
\hline Case Rep Oncol 2016;9:530-536 \\
\hline DOI: 10.1159/000449154 & $\begin{array}{l}\text { C 2016 The Author(s). Published by S. Karger AG, Basel } \\
\text { www.karger.com/cro }\end{array}$ \\
\hline
\end{tabular}

Ergenc et al.: Bilateral Choroidal Metastases from Lung Adenocarcinoma: A Case Report

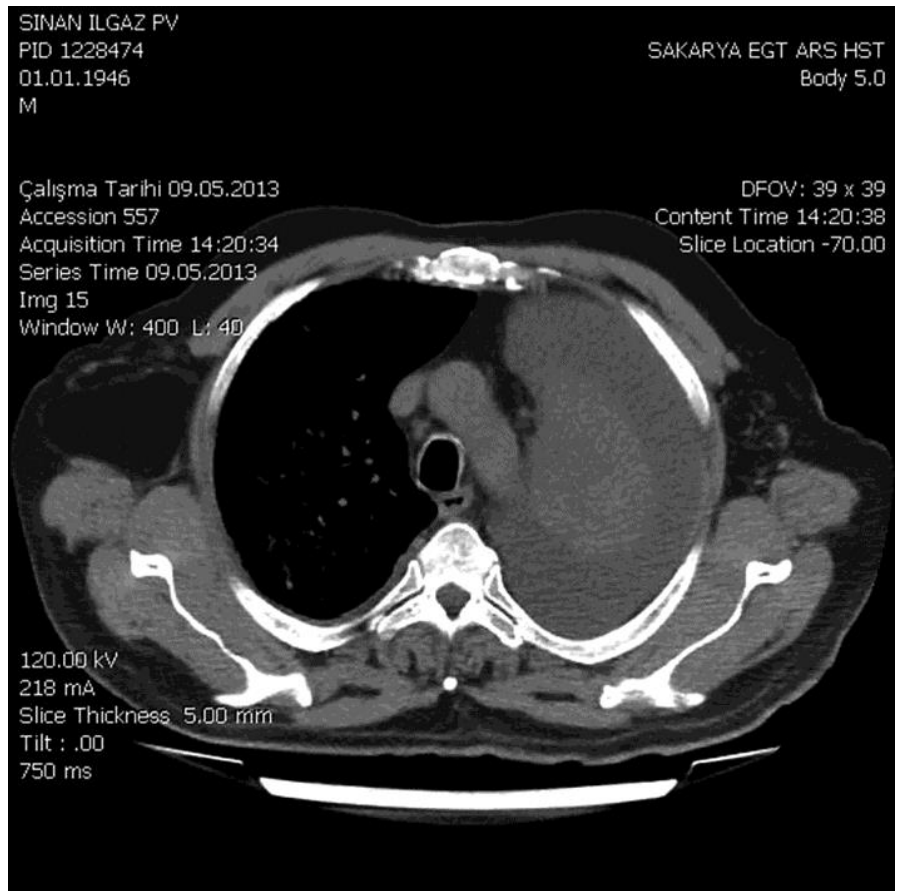

Fig. 1. Multiple nodular lesions in bilateral lungs and left pleural effusion on thorax CT.

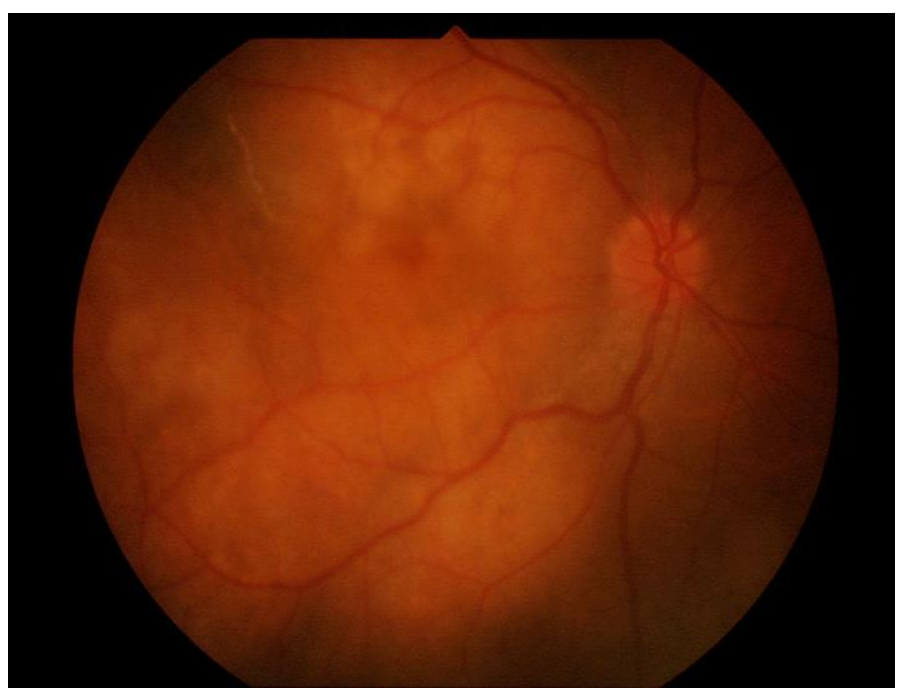

Fig. 2. Unclear boundaries, yellow-white choroidal pock in the right eye fundus examination. 


\section{Case Reports in Oncology}

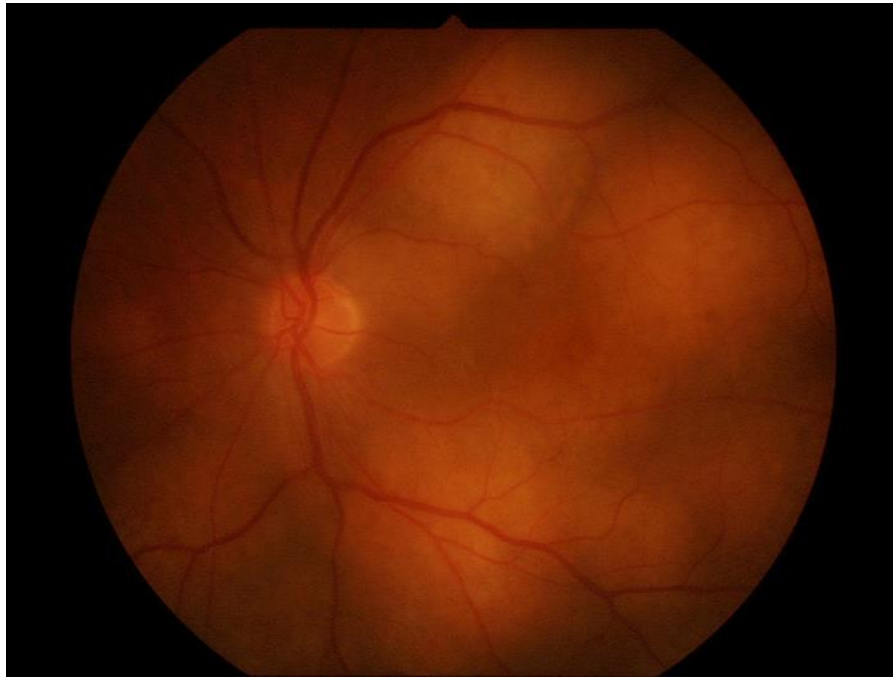

Fig. 3. Yellow choroidal lesions and retinal detachment in the left eye fundus examination.

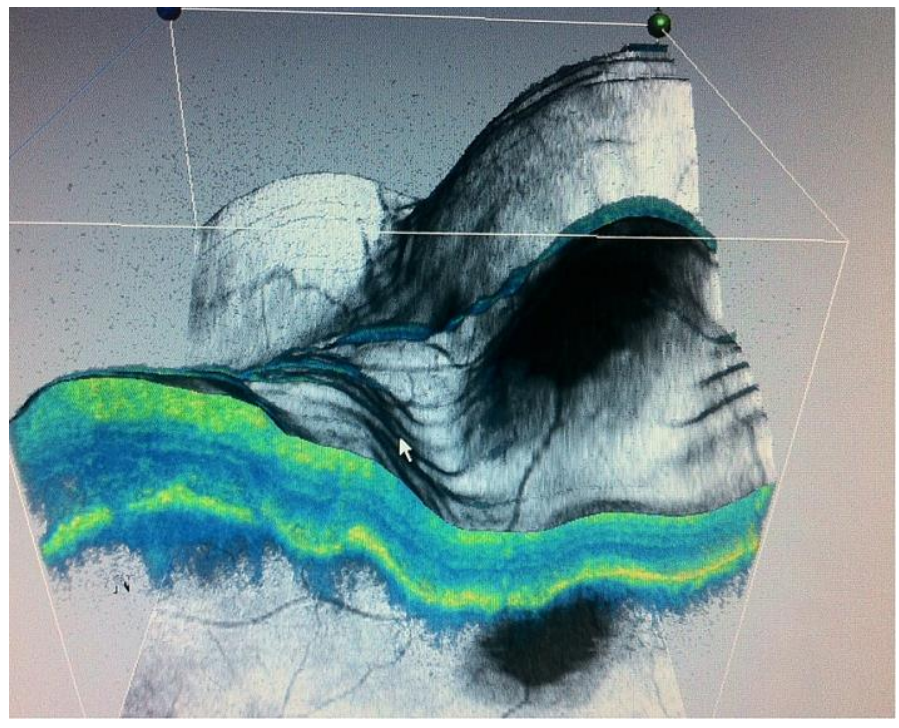

Fig. 4. Retinal pock and choroidal irregularities, 3D OCT in the left eye image. 


\section{Case Reports in Oncology}

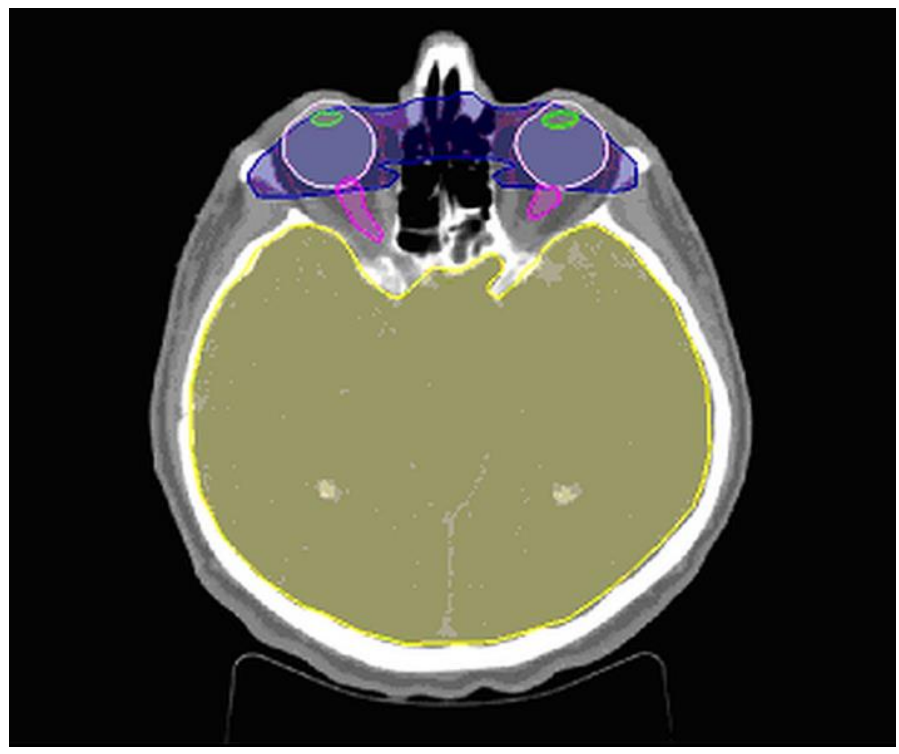

Fig. 5. The radiation field excluding the neural parenchyma. 